$\sqrt{3}$

J. bio-sci. 20: 115-123, 2012

ISSN 1023-8654

http://www.banglajol.info/index.php/JBS/index

\title{
ANTIBACTERIAL ACTIVITY OF TWO VARIETIES OF WATER CHESTNUTS (TRAPA SP.)
}

\author{
Kamal Krishna Biswas ${ }^{1}$, M Omar Faruk ${ }^{1}$, M Ziaul Amin ${ }^{2}$, Ranajit Kumar Shaha ${ }^{1}$ \\ ${ }^{1}$ Dept. of Biochemistry and Molecular Biology, University of Rajshahi, Rajshahi- 6205, Bangladesh \\ ${ }^{2}$ Dept. of Genetic Engineering and Biotechnology, Jessore Science and Technology, University, \\ Jessore-7408, Bangladesh
}

\begin{abstract}
Context: Water chest nut (Trapa sp.), an aquatic fruit plant has been used in some area of the rural people of Bangladesh for the treatment of some chronic diseases.

Objective: The main objective of this study is to investigate the antibacterial activities of the two varieties (red and green) of water chest nuts.

Material and Methods: The antibacterial activities of the methanol extracts of two varieties of water chestnut fruits were studied against a number of human pathogenic bacterial species by using the disc diffusion method. The antibiotic Kanamycin $(30 \mu \mathrm{g})$ was used as standard.

Results: The methanol extract of red variety of water chestnut showed high antibacterial potential (31 $\mathrm{mm}$ ) against Bacillus subtilis at concentration of $600 \mu \mathrm{g}$. On the other hand, green variety showed highest antibacterial activities $(12 \mathrm{~mm})$ against Staphylococcus aureus at concentration of $600 \mu \mathrm{g} . \mathrm{In}$ disc diffusion assay, the methanol extract of red variety was found to have a significant antibacterial efficiency as compared to the methanol extract of green variety of water chestnut.

Conclusion: These findings pinpoint the efficiency of these extracts to inhibit microbial growth. It may lead to the development of a new phyto-medicine.
\end{abstract}

Key words: Trapa fruit, methanol extract, antibacterial activities, Bacillus subtilis, disc diffusion assay.

\section{Introduction}

Water chestnut is an annual aquatic dicotyledonous plant commonly known as "Singhara" or "Paniphol" in Bangladesh. Several varieties are grown in Bangladesh among which Trapa bispinosa Roxb. and Trapa natans $L$. are important. It grows well in shallow fresh water basin in the tropical, sub-tropical and temperate zone of the world (Daniel et al 1983, Kumar et. al. 1985). Trapa bispinosa has two varieties, one is red (Leaf, petiole and fruit) and the other is green (Leaf, petiole and fruit). Both of the fruit is large in size having four dull spines. It has been commercially cultivated in India, Japan, China, Pakistan, Srilanka and different parts of Southeast Asia (Kumar et. al. 1985, Mazumdar 1985).

Water chestnut is a seasonal fruit that grows well everywhere in Bangladesh. Now-a-days a large number of people have been eating this delicious fruit for its rich nutrient contents (Pandit and Quadri 1986) as well as low price. For human consumption water chestnut is eaten in many countries as raw, boiled or roasted and its stem or leaves as vegetables or flavor, or is added in other dishes.

The fruit has also been used in medicinal purposes e.g. in rheumatism and sunburn (Kosuge et al. 1985). The plant has a folkloric reputation as a cure for various diseases. The acrid juice is used for diarrhea, dysentery (Vhotracharcho 1987) and the fruits are also used in aphrodisiac, astringent to the bowels, leprosy, inflammations, urinary discharges, fractures, sore throat, bronchitis, leucorrhoea, bad teeth and malaria (Kirtikar and Basu 1994).

\footnotetext{
*Corresponding author E-mail: kkbiswas@ru.ac.bd
} 
It is well established that natural products play an important role for drug development programs in pharmaceutical industry (Baker et al. 1995, Cordell 1995). The demand on plant-based therapeutics is increasing in both developing and developed countries due to their recognition as natural products, nonnarcotic, readily biodegradable, has no adverse side-effects and availability at affordable prices. Medicinal plants have been used for centuries before the advent of orthodox medicine. Leaves, flowers, stems, roots, seeds, fruit and bark of plant are the constituents of herbal medicines.

Secondary metabolites (photochemical) of plants are extensively found at different levels in various medicinal plants and used in herbal medicine to treat diverse ailments such as cough, malaria, wounds, toothache and rheumatism diseases (Exarchou et al. 2002) and protection of crops. In recent years, the growing demand for herbal product has led to a quantum jump in volume of plant materials traded within and across the countries. Species used in traditional medicine continue to be the most reliable source for the discovery of useful compounds and screening of plants (Ben et al. 1992, Broekaert et al. 1997, Dubery et al. 1999, Hanawa et al. 1992, Kruger and Manion 1994, Mohamed and Sehgal 1997, Pernas et al. 2000). It has opened another source of compounds useful inhibitory activities against different microbes. Hence there is a constant need to establish and develop antimicrobial drugs from natural origin that are much safe, reliable and less expensive. There are hundreds of medicinal plants which have a long history of curative properties against various diseases. However, screening of plants for their activity is very essential and needs urgent attention in order to know the value of the higher plant.

Over the last 20 years, a large number of secondary metabolites from different plant species have been evaluated for their antimicrobial activity. Microorganisms have developed resistance to many antibiotics and this has created vast clinical inconvenience in the treatment of infectious diseases (Davis 1994). The screening of the plants for their biological activity is done on the basis of their chemotaxonomic investigation or ethno-botanical knowledge for a particular disease. Identification of a particular compound against a specific disease is a challenging issue. The increase in resistance to microorganisms due to the indiscriminate use of antimicrobial drugs forced scientists to search for new antimicrobial substances from various sources including medicinal plants (Karaman et al. 2003). A significant portion of the agricultural products in the world has become unfit for human consumption due to mycotoxins contamination of grains (Chandra and Sarbhoy 1997). The main toxic effects are carcinogenicity, genotoxicity, nephrotoxicity, hepatotoxicity, reproductive disorders and immune-supression (Desjardins et al. 2000, Lacey 1998). A large portion of world population is living below poverty line in the developing and under-developing countries. People are also suffering from health problems associated with consuming mycotoxin contaminated grains and cereals (Majumder et al. 1997). Besides this the infectious diseases also account for high proportion of health problems in the developing countries (Sashi et al., 2003).

As plant extract of many higher plant have been reported to exhibit antibacterial activities under laboratory trials (Bouamama et al. 2006, Ergene et al. 2006). Thus it need to search for a compound to protect against various infectious diseases without any toxicity problem that are eco-friendly and inexpensive. Trapa bispinosa Roxb., is such an aquatic annual fruit plant of Trapaceae family comprising about 30 species that are distributed in tropical, sub tropical and temperate zone (Daniel et al. 1983, Kumar et al. 1985, Kusum and Chandra 1980, Mazumdar 1985, Srivastva and Tandon 1951) with high pharmaceutical value.

Keeping all these in mind in this study, an attempt was made to investigate in details of the water chestnut fruits using locally available two varieties (green and red). Although it has pharmaceutical value but there are some limited work done on water chestnut. Therefore the present study was undertaken with the view to investigate the antibacterial activities of the two varieties (red and green) of water chest nuts. 


\section{Materials and Methods \\ Plant materials:}

Mature fresh fruits of two varieties of Trapa sp. for extraction were used as plant material. Two varieties (Red and Green) of Trapa bispinosa Roxb were collected from the Fruit Research Substation, Shyampur, Rajshahi, Bangladesh.

\section{Test organisms}

Eight pathogenic bacteria including five strains of gram-positive (Staphylococcus aureus, Bacillus subtilis, Bacillus megaterium, Sarcina lutea and Bacillus cereus) and three strains of gram-negative (Escherichia coli, Salmonella typhi and Shigella sonnei) were used for the bioassay study. The pure strain was identified and obtained from Genetic Engineering and Biotechnology Laboratory, Department of Botany, University of Rajshahi, Rajshahi 6205, Bangladesh.

\section{Preparation of fresh culture:}

The nutrient agar medium was prepared and dispersed in a number of clean test tubes to prepare slants $(5 \mathrm{ml}$ in each test tube). The test tubes were plugged with cotton and sterilized for 30 mins. After sterilization, the test tubes were kept in an inclined position $\left(45^{\circ} \mathrm{C}\right)$ for solidification. The test organisms were transferred to the agar slants from the supplied pure cultures with the help of an inoculating loop in an aseptic condition. The inoculated slants were then incubated at $37.5^{\circ} \mathrm{C}$ for $24 \mathrm{hrs}$ to ensure the growth of test organisms. These fresh cultures were used for the sensitivity test.

\section{Preparation of the test plates:}

Nutrient agar media were transferred to sterile Petri dishes in aseptic condition. The media were poured into Petri dishes in such a way to keep a uniform depth of approximately $4 \mathrm{~mm}$. The Petri dishes were rotated several times, initially clockwise and then anticlockwise. Test organism $(200 \mu l)$ cultured in nutrient broth media was spread on the surface of solid nutrient agar media and kept preserved for applying samples and standard discs.

\section{Preparation of test sample:}

For preparing the test sample, three different concentrations $(5 \mathrm{mg}, 10 \mathrm{mg}$ and $20 \mathrm{mg}$ ) of methanol extract (ME) of each water chestnuts sample (Red and Green) were dissolved in $0.5 \mathrm{ml}$ water in separate glass vial. The concentrations were $10 \mu \mathrm{g} / \mu \mathrm{l}, 20 \mu \mathrm{g} / \mu \mathrm{l}$ and $40 \mu \mathrm{g} / \mu \mathrm{l}$, respectively for each extract.

\section{Preparation of discs:}

Three types of discs were prepared for antibacterial screening. Sterilized (BBL, USA) filter paper discs ( $5 \mathrm{~mm}$ in diameter) were prepared with the help of punch machine and were taken in blank Petri dishes. Sample solution of desired concentration (10 $\mathrm{\mu l} / \mathrm{disc})$ was applied on the discs with the help of a micropipette in an aseptic condition. These were used to compare the antibacterial activity of test material. In our investigation, Kanamycin $(30 \mu \mathrm{g} / \mathrm{disc})$ was used as standard disc. These were prepared by using identical filter paper $(5$ $\mathrm{mm}$ diameter) and same volume of residual solvent in the same condition. These were used as negative control to ensure that the residual solvent and the filter paper themselves was not active.

\section{Placement of the discs and incubation:}

The dried crude extract discs and standard discs were placed gently as $20 \mathrm{~mm}$ apart from each other and 15 $\mathrm{mm}$ far from the edge of the plate to prevent overlapping the zones of inhibition on the solidified agar plates seeded with the test organisms. The plates were kept in a refrigerator at $4^{\circ} \mathrm{C}$ for $24 \mathrm{hrs}$ in order to provide sufficient time to diffuse the antibiotics into the medium. Then the plates were incubated at $37.5^{\circ} \mathrm{C}$ for $24 \mathrm{hrs}$ in an incubator. 


\section{Measurement of the zones of inhibition:}

After incubation, the antibacterial activities of the test samples were determined by measuring the diameter of inhibitory zones $(\mathrm{mm})$ with a transparent scale.

\section{Results}

The antimicrobial activity of the methanol extract having different concentrations $(200 \mu \mathrm{g} / \mathrm{disc}, 400 \mu \mathrm{g} / \mathrm{disc}$ and

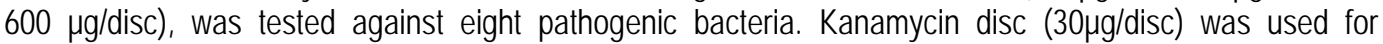
comparing the antibacterial activity. Figure $1(\mathrm{a}-\mathrm{f})$ and Table 1 represent the inhibition zone, found by the activity of isolated methanol extract (ME) of red variety of water chestnut having different concentration (200 $\mu \mathrm{g} / \mathrm{disc}, 400 \mu \mathrm{g} / \mathrm{disc}$ and $600 \mu \mathrm{g} / \mathrm{disc}$ ) tested against eight bacteria and standard antibiotic Kanamycin (30 $\mu \mathrm{g} / \mathrm{disc}$ ). At $200 \mu \mathrm{g} / \mathrm{disc}$ dosage methanol extract of red variety of water chestnut showed 12, 23, 18, 18, 15 and $13 \mathrm{~mm}$ zone of inhibition against S. aureus, B. subtilis, S. lutea, B. cereus, E. coli and S. typhi, respectively. However no antimicrobial activity was observed against Bacillus megaterium and Shigella sonnei at the same concentration.

Table 1. Antibacterial activity of methanol extracts of red and green variety of water chestnut.

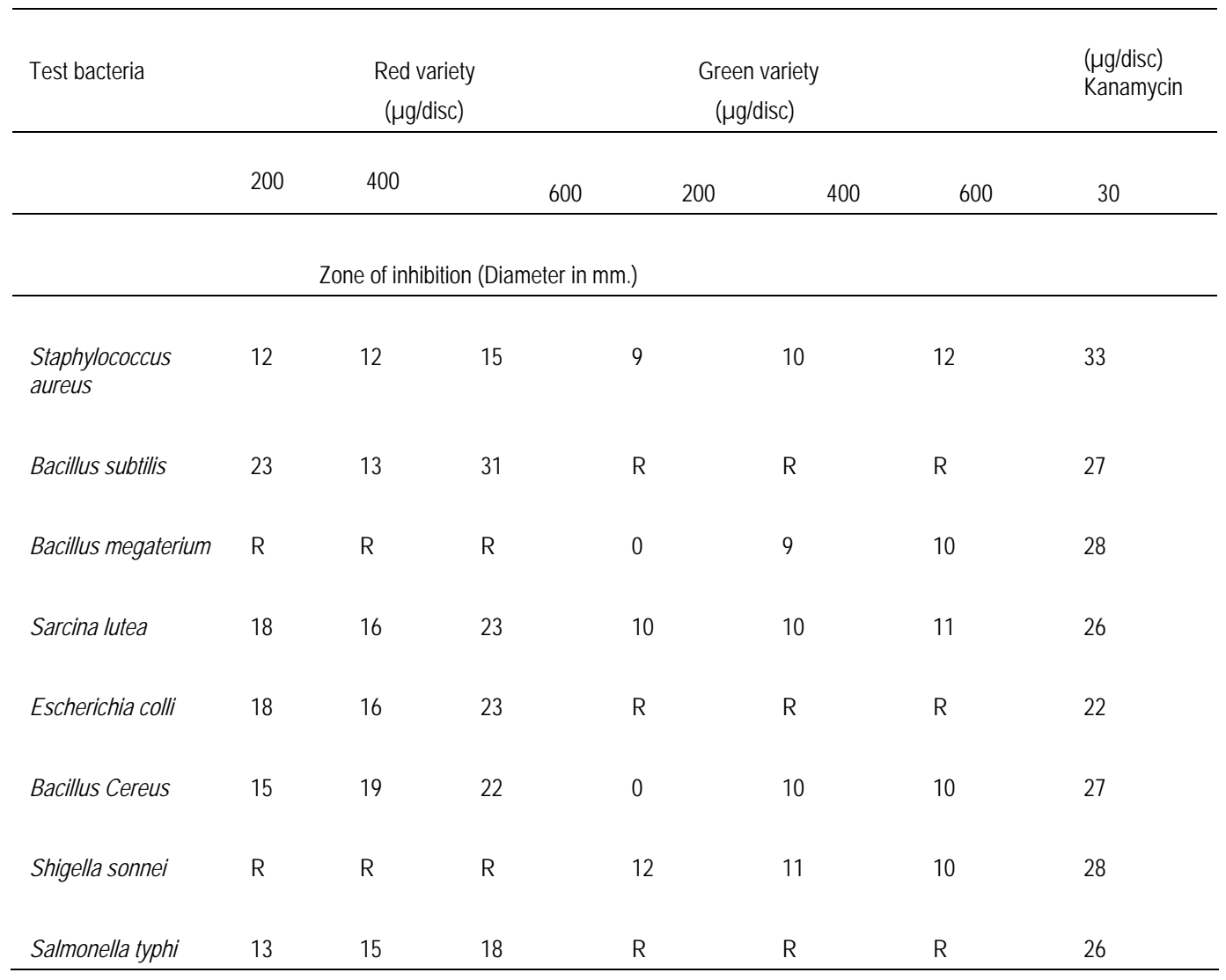

$\mathrm{R}=$ Resistant 


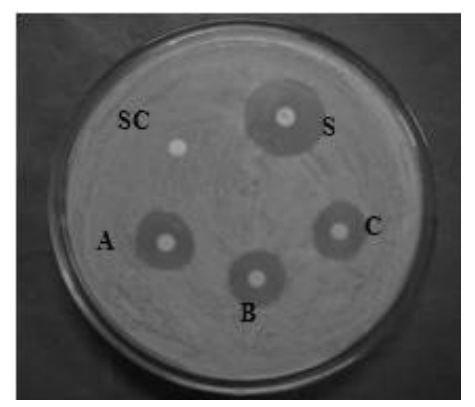

(a) Methanol extract (Red) on Staphylococcus aureus

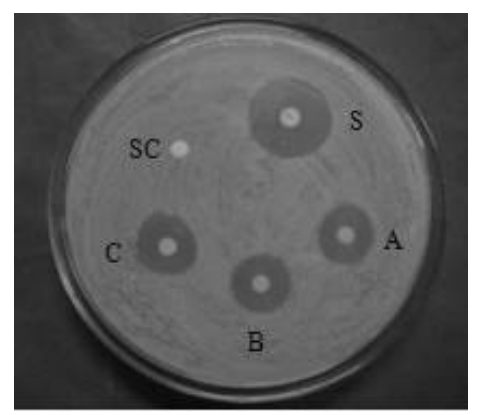

(c) Methanol extract (Red) on Sarcina lutea

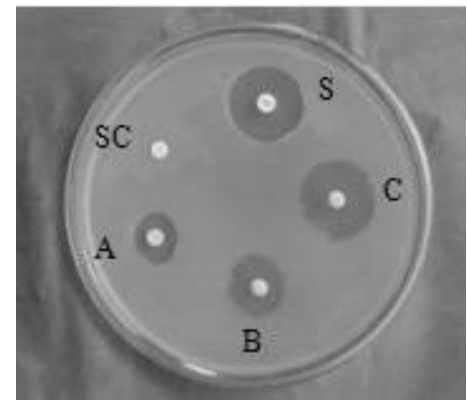

(e) Methanol extract (Red) on Bacillus cereus

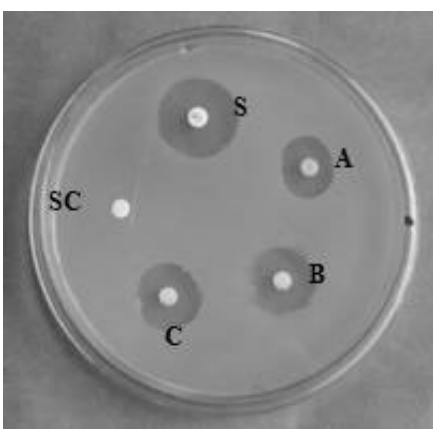

(b) Methanol extract(Red) on Bacillus subtilis

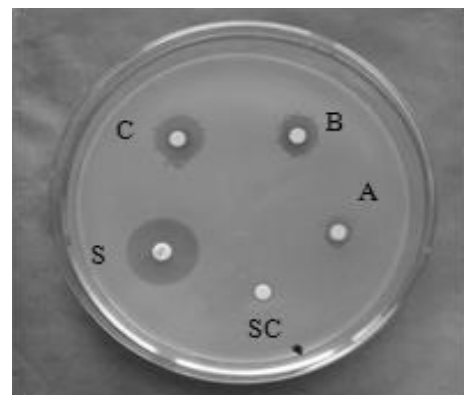

(d) Methanol extract (Red) on Escherichia coli

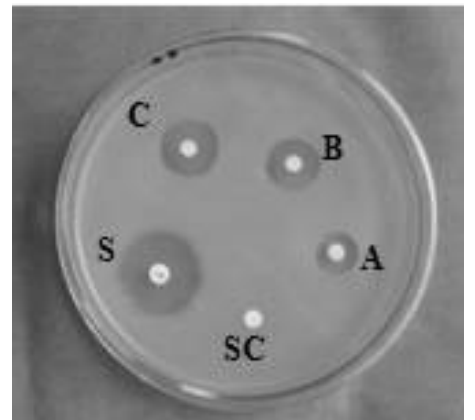

(f) Methanol extract (Red) on Salmonella typhi

Fig.1. Antimicrobial activity of methanol extract of water chestnuts (Red) on six pathogenic bacteria as compared to standard antibiotic Kanamycin by using disc diffusion method. (a-f) indicates the antibacterial activities of methanol extract of water chestnut (Red) against six bacteria (a) Stappylococcus aureus (b) Bacillus subtilis (C) Sarcina lutea (d)

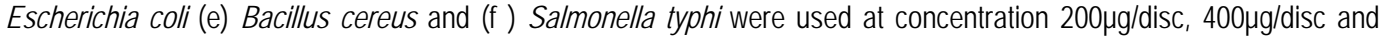
$600 \mu \mathrm{g} / \mathrm{disc}$ respectively. Standard antibiotic disc Kanamycin(30 $\mathrm{g} / \mathrm{disc})$ was used for comparison. SC- indicates solvent control A- indicates $200 \mu \mathrm{g} / \mathrm{disc}$ B- indicates $400 \mu \mathrm{g} /$ disc C- indicates $600 \mu \mathrm{g} / \mathrm{disc}$ and S- indicates Kanamycin $(30 \mu \mathrm{g}$ /disc), respectively. 


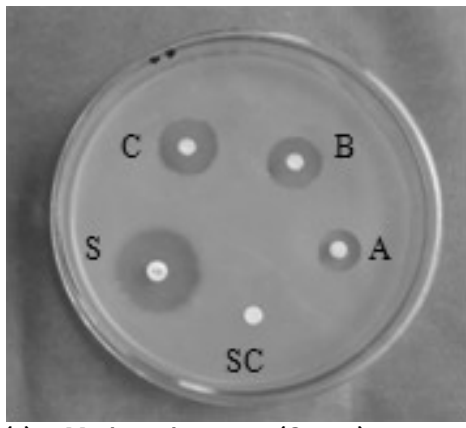

(a) Methanol extract (Green) on Staphylococcus aureus

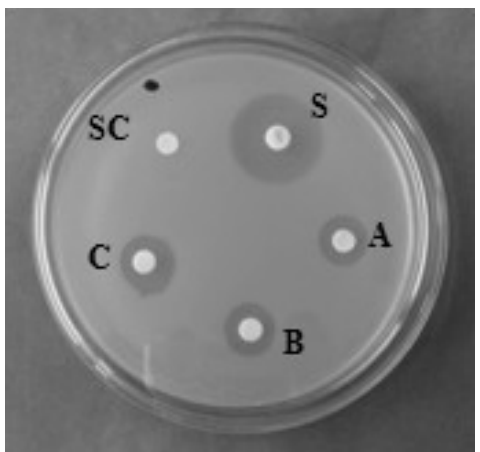

(c) Methanol extract (Green) on Shigella sonnei

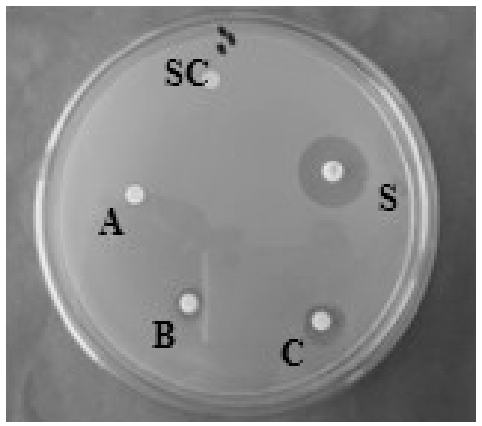

(e) Methanol extract (Green) on Bacillus megatorium

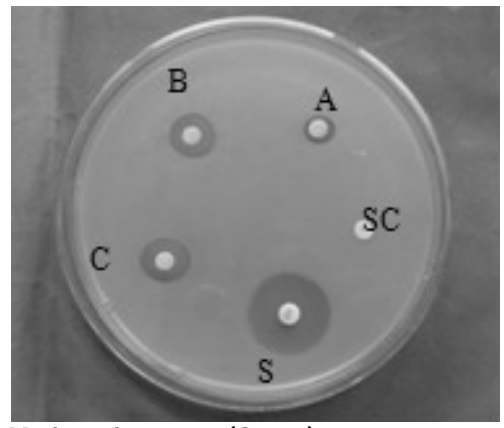

(b) Methanol extract (Green) on Bacillus cereus

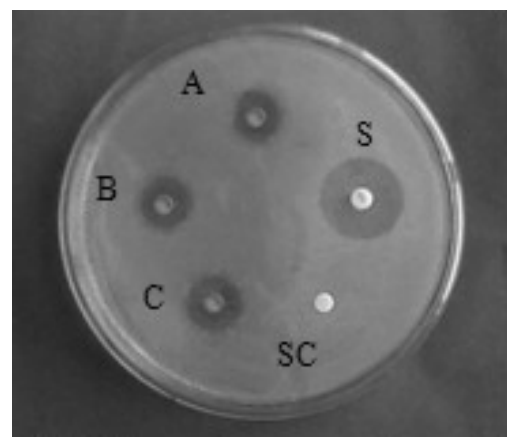

(d) Methanol extract (Green) on Sarcina lutea

$\mathrm{SC}=$ Solvent control

$A=200 \mu \mathrm{g} / \mathrm{disc}$

$\mathrm{B}=400 \mu \mathrm{g} / \mathrm{disc}$

$\mathrm{C}=600 \mu \mathrm{g} / \mathrm{disc}$

$\mathrm{S}=$ Kanamycin $(30 \mu \mathrm{g} / \mathrm{disc})$

Fig. 2. Antimicrobial activity methanol extract of water chestnuts (Green) on five bacteria as compared to standard antibiotic Kanamycin by using disc diffusion method. (a-e) indicates the antibacterial activities of methanol extract of water chestnut (Green) against five bacteria (a) S. aureus (b) B. cereus (C) S. sonnei (d)

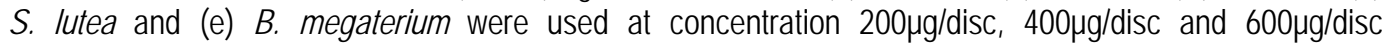
respectively. Standard antibiotic disc Kanamycin (30 $\mathrm{gg} / \mathrm{disc})$ was used for comparison. SC- indicates solvent control A- indicates $200 \mu \mathrm{g} / \mathrm{disc}$ B-indicates $400 \mu \mathrm{g} /$ disc C- indicates $600 \mu \mathrm{g} / \mathrm{disc}$ and S- indicates Kanamycin $(30 \mu \mathrm{g} / \mathrm{disc})$, respectively. 
As shown in Fig. 1 and Table 1 in case of methanol extract of red variety of chestnut at 400 $\mu$ g/disc concentration, the zone of inhibition against the same bacteria were 12,13,16,16,19, and 15mm respectively. In case of highest dose of $600 \mu \mathrm{g} / \mathrm{disc}$, the zones of inhibition were found to be $15,31,23,23$, 22, and $18 \mathrm{~mm}$, respectively. As shown in Table 1 also two bacteria Bacillus megaterium and Shigella sonnei were resistant to $200 \mu \mathrm{g} / \mathrm{disc}, 400 \mu \mathrm{g} / \mathrm{disc}$ and $600 \mu \mathrm{g} / \mathrm{disc}$ dosages methanol extract of red variety (Not shown in Fig. 1). But the standard antibiotic disc Kanamycin (30 $\mu \mathrm{g} / \mathrm{disc})$ showed the zone of inhibition against eight bacteria such as Staphylococcus aureus, Bacillus subtilis, Bacillus megaterium Sarcina lutea, Escherichia coli, Bacillus cereus, Shigella sonnei and salmonella typhi .The zones of inhibitions were 33, 27, $28,26,22,27,28$ and $26 \mathrm{~mm}$ respectively (Table 1).

On the other hand the antimicrobial activity of the methanol extract of green variety of water chestnut against Staphylococcus aureus, Bacillus megaterium, Sarcina lutea, Bacillus cereus and Shigella sonnei, were 9, $0,10,0$ and 12,mm at $200 \mu \mathrm{g} / \mathrm{disc}$ dosage respectively (Table 1 and Fig. 2). At $400 \mathrm{n} \mu \mathrm{g} / \mathrm{disc}$ dosage green variety of methanol extract produced 10, 9, 10,10 and $11 \mathrm{~mm}$ of inhibition zone against the same bacteria respectively (table 1 and Fig. 2). Highest dosage of $(600 \mu \mathrm{g} / \mathrm{disc})$ of methanol extract of green variety was also able to produce zone of inhibition resulting $12,10,11,10$ and $10 \mathrm{~mm}$ respectively (Table1 and Fig. 2). The resistance was observed in case of the methanol extract of green variety of water chest nut against three bacteria like Bacillus subtilis, Escherichia colli and Salmonella typhi respectively ( not shown in Fig.2 but data shown in Table 1).

\section{Discussion}

The aqueous extract of both the red and green variety of water chest nut found to be effective against all the pathogenic bacteria by disc diffusion assay. It exhibited reasonable antibacterial activity against all the tested bacteria. The methanol extract of water chestnut (green varieties) showed notable antibacterial efficiency (9$12 \mathrm{~mm}$ ) against most of the tested organisms except, Bacillus subtilis, Escherichia coli, Salmonella typhi. Highest antibacterial activity was observed against Shigella sonnei $(12 \mathrm{~mm})$ bacteria when applied 200 $\mu \mathrm{g} / \mathrm{disc}$ dosages (Table $1 \&$ Fig. 2c).

Table 1 and Fig. 2a represent the poor efficiency against the Staphylococcus aureus $(9 \mathrm{~mm})$ which is lower than Kanamycin $(33 \mathrm{~mm})$. From Table 1 and Figure $1 \mathrm{It}$ is also revealed that fruit extract of water chestnut (red variety) showed the most effectiveness $(12-31 \mathrm{~mm})$ against all pathogenic bacteria except Bacillus megaterium and Shigella sonnei. Highest inhibitory activity was found against Bacillus subtilis (31 mm)

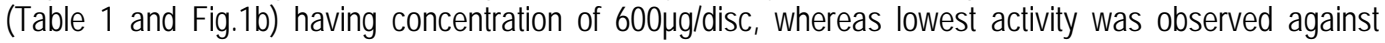
Staphylococcus aureus (12 mm) ( Fig.1a and Table 1) Bacillus subtilis, Escherichia coli and Salmonella typhi were resistant to the green variety but sensitive to red variety of water chestnut fruit (table 1). Beside this Bacillus megaterium was found to be resistant to red variety though it showed a little bit sensitivity against green variety of water chestnut fruit extract. This result indicates that the fruit extract from green \& red varieties of water chestnut also act as inhibiting agent against some bacteria. Nascimento et.al 2000 also reported that Caryophyllus aromaticus and Syzygyum joabolanum extracts showed promising inhibitory growth of Pseudomonas aeruginosa.

In the present study the fruit extract of red water chestnut was more effective than green water chestnut against all the pathogenic bacteria tested by the disc diffusion assay. It is also reported that the leaves extract of Pistacia lentiscus and Pistacia arlantica have been proved to be very effective against eight bacteria, five moulds \& yeast by disc diffusion method (Benhammou et al. 2008).

The methanol extract of red variety of water chestnut fruit was found to be the most potential antibacterial extract that showed inhibitory activity against both gram (+ ve) and gram (- ve) bacteria. This study reveals that water chestnut can be used potentially as a broad spectrum antibacterial agent. Considering the cost, 
availability and extractability percentage of the aqueous extract, it can also be used as a cheap alternative to substitute antibiotics. The increase of antibiotic resistance of microorganisms to conventional drugs has necessitated the search for new, efficient and cost effective ways for the control of infectious diseases. The results of different studies provide evidence that some medicinal plants might indeed be potential sources of new antibacterial agents (Kone et al., 2004).

It can be concluded that water chestnut (Trapa spp.) has a wide range of antibacterial activity and supports the traditional use of these plants as medicines. This study also demonstrated that herbal medicine can be as effective as modern medicine to combat pathogenic microorganisms. This work has highlighted the antimicrobial effects of fruit extract of $T$. bispinosa on some of the medically important pathogens and opens a new window and suggests the potentialities of these extracts as antibacterial agent. Hence, $T$. bispinosa fruit could be used as a guide in our continuing search for new natural products with potential medicinal properties as it will lead to the development of a phyto-medicine to act against microbes.

\section{References}

Baker JT, Borris RP, Carte B, Cordell GA, Soejarto DD, Cragg GM, Gupta MP, IwU MM, Madulid DR, Tyler VE. 1995. Natural product drug discovery and development. New perspective on international collaboration. Journal of Natural Product 58, 1325-1357. http://dx.doi.org/10.1021/np50123a003

Beck E. 1985. The degradation of transitory starch granules in chloroplast. In R Health, J Preiss, eds. Regulation of Carbon Partitioning in Photosynthetic Tissue. American Society of Plant Physiologists, Rockvile, MD. 27-44 pp.

Benhammou N, Bekkara FA and Panovska TK. 2008. Antioxidant and antimicrobial activities of the pistacia lentiscus and pistacia atlantica exracts. African Journal of Pharmacy and Pharmacology 2(2), 22-28. http://dx.doi.org/10.1016/i.jep.2005.08.062

Ben YS, Rodov V, Kim JJ, Carmeli S. 1992. Preformed and Phytopathology 50, 458-68.

Bouamama H, Noel T, Villard J, Benharref A, Jana M. 2006. Antimicrobial activities of the leaf extracts of two Moroccan Cistus L. species. Journal of Ethnopharmacology 104, 104-107.

Broekaert W, Cammue B; Debolle M, Thevissen K, Desamblanx G and Osborn R. 1997. Antimicrobial peptides from plants. Critical Reviews in Plant Sciences 16(3), 297-323. http://dx.doi.org/10.1080/713608148

Chandra R, Sarbhoy AK. 1997. Production of Aflatoxins and Zearalenone by the toxigenic fungal isolates obtained from stored food grains of commercialcrops. Indian Phytopathology 50, 458-468.

Cordell GA. 1995. Changing strategies in natural products chemistry. Phytochemistry 40, 1585-1612. http://dx.doi.org/10.1016/0031-9422(95)00444-C

Davis J. 1994. Inactivation of antibiotics and the dissemination of resistance genes. Science 264, 375- 382. http://dx.doi.org/10.1126/science.8153624

Desjardins AE, Manandhar G, Plattner RD, Maragos, CM, Shrestha K, McCormick SP. 2000. Occurrence of Fusarium species and mycotoxins in Nepalese Maize and Wheat and the effect traditional processing method on mycotoxin levels. Journal of Agricultural and Food Chemistry 48, 1377-1383. http://dx.doi.org/10.1021/f991022b

Dubery IA, Louw AE, van Heerden FR. 1999. Synthesis and evaluation of 4 - (3 methyl - 2 -butenoxy), a radiationinduced stress metabolites in citrus. Phytochemistry 50(6), 983-989. http://dx.doi.org/10.1016/S0031-9422(98)00247-7

Ergene A, Guler P, Tan S, Mirici S, Hamzaoglu E, Duran A. 2006. Antibacterial and antifungal activity of Heracleum sphondylium subsp. Artvinense. African Journal of Biotechnology 5, 1087-1089. 
Exarchou V, Nenadis N, Tsimidou M, Gerothanassis IP, Trogains A, Boskou D. 2002. Antioxidant activities and phenolic composition of extracts from Greek oregano, Greeksage and summer savory. Journal of Agricultural and Food chemistry 50, 5294-5299. http://dx.doi.org/10.1021/ff020408a

Hanawa F, Tahara S, Mizutani J. 1992. Antifungal stress compounds from Veratrum grandiflorum leaves treated with cupric chloride. Phytochemistry 31, 3005-3007. http://dx.doi.org/10.1016/0031-9422(92)83436-3

Karaman I, Sahin P, Gulluce M, Oguten H, Songul M, Adiguzed A. 2003. Antimicrobial activity of aqueous and methanol extracts of Juniperus oxycedrus L. Journal of Ethnopharmacolology 85 (2-3), 231-235. http://dx.doi.org/10.1016/S03788741(03)00006-0

Kirtikar BD, Bashu BD. 1994. Indian Medicinal plants. vol. 3. International Book Distributors, Deheradun, India.

Kone WM, Atindehou KK, Terreaux C, Hostettmann K, Traore D, Dosso M. 2004. Traditional medicine in North Coted'Ivoire: screening of 50 medicinal plants for antibacterial activity. Journal of Ethnopharmacolology 93, 43-49. http://dx.doi.org/10.1016/j.jep.2004.03.006

Kosuge, T, M. Yokoto, Suglyara K. 1985. Studies on antitumour activities and antitumous principle of Chinese herbs,1. Antitumour activities of Chinese herb. Yakugaku Zasshi 105, 791-795.

Kruger BM, Manion PD. 1994. Antifungal compounds in aspen: effects of water stress. Can J Bot 72, 454-460. http://dx.doi.org/10.1139/b94-060

Kumar L, Sing SP, Pahuja SS. 1985. Studies on vegetative reproduction rate of water hyacinth and water chestnut. Indian J Agric Res 19, 54-58.

Kusum B, Chandra V. 1980. Water Chestnut (Trapa): A supplement to cereals and a conserver of river in waste land. Biol Member , 5, 12.

Lacey J. 1988. The microbiology of cereal grains from areas of Iran with a high incidence of oesophageal cancer. Journal of Stored Product Research 24: 39-50. http://dx.doi.org/10.1016/0022-474X(88)90007-0

Mazumdar BC. 1985. Water Chestnut the Aquatic Fruit. Wild Crops 37, 42- 44.

Majumder UK, Gupta M, Mukhopadhyay DK. 1997. Effect of mycotoxins isolated from penicillium nigricans on glucose-6phosphated dehydrogenase. Indian Journal of Experimental Biology 35, 1233-1236.

Mohamed F, Sehgal OP.1997. Charcteristic of pathogenesis related proteins induced Phaseolus vulgaris cv.Pinto following virul infection. Journal of Phytopathology 145, 49-58. http://dx.doi.org/10.1111/.1439-0434.1997.tb00364.x

Pandit, AK, Quadri MY. 1986. Nutritive value of some aquatic life forms of Kashmir. Environ Conver 13, 260-262.

Pernas M, Sanchez-Monge R, Salcedo G. 2000. Biotic and abiotic stress can induce cystatin expression in chestnut. FEBS Letters 467, 206-210. http://dx.doi.org/10.1016/S0014-5793(00)01157-1

Sashi KJ, Ramya M, Janardhan K. 2003. Antimicrobial activity of ethnomedicinal plants of Nilgiri Biosphere reserve and Western Ghats. Asian J Microbiol Biotechnol Environ Sci 5, 183- 185.

Srivastva GD, Tandon RK.1951. Study in the autecology of Trapa bisinosa Roxb Proc Natl Acad Sci India B. 21: 57- 66.

Vhotracharcho C. 1987. Chironjib Banaushadhi. 2, 96-100. 